\title{
PREVALENCE, DISTRIBUTION AND DETERMINANTS OF INTESTINAL TUBERCULOSIS IN ADULT INDOOR PATIENTS WITH ACUTE SMALL INTESTINAL OBSTRUCTION IN POPULATION OF PESHAWAR DIVISION, PAKISTAN
}

\author{
Aftab Hussain', Sheikh Muhammad Ibqar Azeem¹, Imran Ullah², Shahidullah Ahmad', Muhammad Faisal \\ Khan $^{3}$, Muddasar Shahzad ${ }^{4}$ \\ Departments of Surgery, ${ }^{1}$ Peshawar Medical College, Peshawar, ${ }^{3}$ Lady Reading Hospital, Peshawar, \\ ${ }^{4}$ Nowshera Medical College, Nowshera, ${ }^{2}$ Department of Health, D.I.Khan, Pakistan
}

\begin{abstract}
Background: Acute small intestinal obstruction (ASIO) is one of the commonest causes of emergency hospital admissions, morbidity and mortality. Intestinal tuberculosis (ITB) is common cause of ASIO in developing countries leading to significant morbidity and mortality. Our objectives were to determine prevalence, distribution and determinants of ITB in adult indoor patients with ASIO in population of Peshawar Division, Pakistan.

Materials \& Methods: This cross-sectional study was conducted at Department of Surgery Peshawar Medical College, Peshawar, Pakistan from January 2019 to June 2020. The data was collected from its three affiliated hospitals; Mercy Teaching Hospital, Kuwait Teaching Hospital \& Prime Teaching Hospital, Peshawar. 207 ASIO subjects were selected from population at risk consecutively. Sex, age groups and presence of ITB were variables. Prevalence and distribution were described by count, percentage and confidence intervals for proportion for population. Hypotheses for distribution were tested by chi-square goodness of fit and of association by chisquare test of association.
\end{abstract}

Results: Out of 207 patients with ASIO, 128 (61.84\%) were men and $79(38.16 \%)$ women, 87 (42.03\%) were in age group 18-40 and 120 (57.97\%) in 41-60 years. Out of 207 patients with ASIO, $41(19.81 \%)$ had ITB, while $166(80.19 \%)$ had no ITB. Out of 41 ITB patients, 25 (12.08\%) were men and $16(7.73 \%)$ women, $17(8.21 \%)$ in age group 18-40 and $24(11.60 \%)$ in 41-60 years. The prevalence of ITB was similar to expected $(p=.5695)$. The distribution across sex $(p=.00001)$ was different and across age groups $(p=.12501)$ was similar to expected. Presence of ITB was not associated to sex $(p=.8992)$ and age groups $(p=.9347)$.

Conclusion: Prevalence of intestinal TB in adult indoor acute small intestinal obstruction (ASIO) population of Peshawar Division, Pakistan was 19.81\%. Prevalence was higher in men than women and higher in 41-60 years than 18-40 years age group population. Overall prevalence of intestinal TB was similar to expected. Observed distribution across sex was different and across age groups was similar to expected. Presence of intestinal TB was not associated to sex and age groups respectively.

KEY WORDS: Intestinal Obstruction; Tuberculosis; Prevalence; Distribution; Determinants; Sex; Age Groups; Pakistan.

Cite as: Hussain A, Azeem SMI, Ullah I, Ahmad S, Khan MF, Shahzad M. Prevalence, distribution and determinants of intestinal tuberculosis in adult indoor patients with acute small intestinal obstruction in population of Peshawar Division, Pakistan. Gomal J Med Sci 2020 Jul-Sep; 18 (3):107-15. https://doi.org/10.46903/gjms/18.03.832

\section{Corresponding Author:}

Dr. Aftab Hussain

Senior Registrar, Department of Surgery

Peshawar Medical College, Peshawar, Pakistan

E-mail: draftabmarwat6@gmail.com

Date Submitted:

07-07-2020

Date Revised:

$09-08-2020$

Date Accepted:
$15-08-2020$

\section{INTRODUCTION}

1.1 Background: Acute small intestinal obstruction (ASIO) is important surgical emergency. ${ }^{1-3}$ It is responsible for $2-4 \%$ of emergency visits, about $15 \%$ hospital admissions, and $20 \%$ of emergency surgeries for abdominal pain. ${ }^{4,5}$ In the United States in 1994 small intestinal obstruction caused about 300,000 admissions, about 846,000 days of indoor care, and approximately 1.3 billion dollars in health care 
cost. ${ }^{6}$ Intestinal ischemia is complicating 7 to $42 \%$ of intestinal obstructions and significantly increases mortality associated with intestinal obstruction. ${ }^{7}$

Adhikari, et al. ${ }^{8}$ from Calcutta, India from May 2005 to April 2008 demonstrated $14.17 \%$ $(52 * 100 / 367=14.17 \%)$ intestinal TB (ITB) cases in 367 patients of acute intestinal obstruction, $7.36 \%\left(27^{*} 100 / 367=7.36 \%\right)$ mortality caused by acute intestinal obstruction out of which $3.82 \%$ $(14 * 100 / 367=3.82 \%)$ mortality was caused by ITB and $3.54 \%\left(13^{*} 100 / 367=3.54 \%\right)$ by other causes respectively.

Tuberculosis (TB) is the $10^{\text {th }}$ important cause of death throughout the world. It is the first leading cause of mortality from a single infection. Globally in 2018, there were about 10 million incident TB cases. Globally 1.2 million deaths in HIV non-infected patients and 251,000 deaths in HIV infected patients were caused by TB. ${ }^{9}$ Pakistan is ranked $5^{\text {th }}$ in 30 high-prevalent countries for TB and $5^{\text {th }}$ for drug-resistant TB. Estimated TB incidence, prevalence and mortality is respectively 267,341 and 27 per 100,000 population with about 525,000 new TB cases annualy. ${ }^{10}$

Intestinal TB is very common in developing countries. ${ }^{11}$ Intestinal obstruction is the most common complication of ITB. ${ }^{12,13}$ Choudhary, et $\mathrm{al}^{14}(n=156)$ from Uttarakhand, India from 2011 to 2016 reported $13.56 \%$ mortality due to tubercular ASIO.

Nguyen, et al. ${ }^{15}$ from Ho Chi Minh, Vietnam from 1992 to $1998(n=513)$ highlighted $4.48 \%$ $(23 * 100 / 513=4.48 \%)$ prevalence of ITB in intestinal obstruction, of which $3.90 \%(20 * 100 / 513=3.90 \%)$ were men and $0.58 \%\left(3^{*} 100 / 513=0.58 \%\right)$ women, $1.36 \%(7 * 100 / 513=1.36 \%)$ were in age group 20 40 years and $3.12 \%(16 * 100 / 513=3.12 \%)$ in $41-70$ years. Chitumalla, et $\mathrm{al}^{16}$ from Hyderabad, India from October 2013 to September 2015 elaborated $4.88 \%$ $(2 * 100 / 41=4.88 \%)$ ITB cases in 41 patients of ASIO.

Tasnim, et al ${ }^{17}$ from Rajshahi, Bangladesh from Sep. 2010 to Aug. 2011 showed $2.8 \%(7 * 100 / 250=$ $2.8 \%$ ) frequency of ITB in 250 patients with intestinal obstruction. Maik, et $\mathrm{al}^{18}$ from Jamshoro, Pakistan from June 2004 to June 2009 demonstrated $25.58 \%\left(55^{*} 100 / 215=25.58 \%\right)$ ITB in 215 ASIO patients. Sultan, et al ${ }^{19}$ from Karachi, Pakistan from September 2016 to October 2019 reported $7.5 \%$ $(9 * 100 / 120=7.5 \%)$ prevalence of ITB in 120 intestinal obstruction cases.

\subsection{Research Problems (RPs), Knowledge Gaps (KGs) \& Rationale}

The first step in solving a problem is to know the overall and group wise burden of the problem/ disease. Thereafter we can work for its determinants (causes/ risk factors) and solution/ treatment. We have adopted "Marwat's Logical Trajectory of Research Process". ${ }^{20-23}$ Unawareness about the prevalence, distribution (across sex and age groups) and determinants (association to sex and age groups) of intestinal TB in adult indoor ASIO population of Peshawar Division, Pakistan are our five RPs. Unavailability of data regarding these RPs are our five knowledge gaps and hence rationale for our project.

\subsection{Research Questions (RQs)}

RQ-1: What is the prevalence of intestinal TB in adult indoor ASIO population of Peshawar Division, Pakistan?

RQ 2-3: What is the distribution of intestinal TB across the sex and age groups in adult indoor ASIO population of Peshawar Division, Pakistan?

RQ 4-5: What is the association between intestinal TB and sex and age group in adult indoor ASIO population of Peshawar Division, Pakistan?

\subsection{Research Objectives (ROs)}

The objectives of our study were to find the:

RO-1: prevalence of intestinal TB in adult indoor ASIO population of Peshawar Division, Pakistan.

RO 2-3: distribution of intestinal TB across the sex and age groups in adult indoor ASIO population of Peshawar Division, Pakistan.

RO 4-5: association between intestinal TB and sex and age group in adult indoor ASIO population of Peshawar Division, Pakistan.

\subsection{Research Hypotheses (Null)}

$\mathbf{H}_{01}$ : The observed prevalence of intestinal TB is similar to expected in adult indoor ASIO population of Peshawar Division, Pakistan. (RQ1, RO1)

$\mathbf{H}_{02}$ : The observed distribution of intestinal TB across the sex is similar to expected in adult indoor ASIO population of Peshawar Division, Pakistan. (RQ2, $\mathrm{RO} 2)$

$\mathbf{H}_{03}$ : The observed distribution of intestinal TB across the age groups is similar to expected in adult indoor ASIO population of Peshawar Division, Pakistan. (RQ3, RO3)

$\mathbf{H}_{04}$ : Presence of intestinal TB and sex are not associated with each other in adult indoor ASIO population of Peshawar Division, Pakistan. (RQ4, RO4)

$\mathbf{H}_{05}$ : Presence of intestinal TB and age groups are not associated with each other in adult indoor ASIO population of Peshawar Division, Pakistan. (RQ5, RO5)

1.6 Significance: This study will determine the burden of the problem i.e. intestinal TB overall and in sex and age groups in adult indoor ASIO population in high TB-prevalent countries like Pakistan. Further this study may identify associations of sex and age groups to ITB in adult indoor ASIO population. It will help the public health specialists and clinicians to plan reasonable steps. 


\section{MATERIALS AND METHODS}

2.1 Design, Setting \& Duration: This cross-sectional study was conducted at the Department of Surgery, Peshawar Medical College, Peshawar, Pakistan from January 2019 to June 2020. The data was collected from its three affiliated hospital; Mercy Teaching Hospital, Kuwait Teaching Hospital \& Prime Teaching Hospital Peshawar.

\subsection{Population, Sample Size \& Technique and} Sample Selection: Peshawar Division (consisting of Districts Peshawar, Nowshera, Charsadda, Khyber and Mohmand) is the most populous division of Khyber Pukhtunkhwa; a province in the north-west of Pakistan. Its population was 8,922,465 in 2017 Census. Age group 18-60 years was assumed to contribute its $50 \%$, hence $4,461,233$ persons. With overall presumed prevalence rate of $0.1 \%$ of $A S I O$ in this age group, the population with ASIO (population at risk) will be around 4,461 $(0.1 * 4,461,233 / 100=$ $4,461)$ persons. With so much population, prevalence rate of $25.58 \%{ }^{9}$ of ITB in this population, margin of error $5.81 \%$ and confidence interval of $95 \%$, sample size was calculated as 207 using online calculator Raosoft ${ }^{\circledR} .{ }^{24}$

Consecutive non-probability sampling technique was used. Adult ( $\geq 18-60$ years) indoor patients with ASIO were eligible for inclusion with no exclusion criteria.

2.3 Conduct of Procedure: All patients with clinical and radiological evidence of ASIO coming to emergency department of hospital were admitted, resuscitated and stabilized. A detailed history and thorough clinical examination was carried out in all the patients. Patients were asked to remain nil per oral and all base-line investigations including CXR were carried out. X-rays abdomen (erect and supine) and ultrasound (abdomen and pelvis) were done in all the patients. Surgical laparotomy was done on the earliest available list. All intestinal specimens/ biopsies were sent for histopathology. Patients with confirmed ITB, when clinically stable, were referred to physician for anti-tuberculosis therapy.

2.4 Data Collection Plan: Secondary data was collected through literature search, while primary data was collected through observation. Primary data was collected for the following two demographic variables (attributes); sex (men, women), age groups (18-40 years, 41-60 years) and one research variable (attributes); presence of ITB (yes, no). The data type was nominal for all these variables.

\subsection{Data Analysis Plan}

2.5.1 Descriptive Analysis and Estimation of Parameters: Descriptively the two demographic and one research variable was analyzed by count and percentage. Estimation of parameters for proportion for the population was given as confidence interval at confidence level of $95 \%$, using Wilson score interval for the binomial distribution through an online statistical calculator. ${ }^{25}$ It would mean that if the confidence interval is calculated for an infinite number of samples with a sample size of $207,95 \%$ of the calculated confidence intervals will contain the true value of the proportion of the population.

\subsubsection{Testing of Hypotheses}

Observed and expected prevalence and observed and expected distribution of ITB by sex and age groups were analyzed separately using chisquare goodness of fit test by an online calculator $\left(\mathrm{H}_{01}-\mathrm{H}_{3}\right) \cdot{ }^{26-28}$ The association between the presence of ITB and sex and age groups was calculated by using chi-square test of association/ independence by an online calculator $\left.\left(\mathrm{H}_{04-05}\right)\right)^{26,27,29}$ Observed counts, expected counts, their difference, chi-square value, degree of freedom and level of significance were given at alpha 05 .

\section{RESULTS}

\subsection{Descriptive Statistics \& Estimation of Param-} eters

3.1.1 Sample Description \& Prevalence of ITB in adult indoor ASIO population: Out of 207 patients with ASIO, 128 (61.84\%) were men and 79 (38.16\%) women, $87(42.03 \%)$ were in age group 18-40 years and $120(57.97 \%)$ in age group 41-60 years.

Out of 207 patients with ASIO, 41 (19.81\%) had ITB, while $166(80.19 \%)$ had no ITB. Estimated prevalence in population is shown below. (Table 3.1.1)

Table 3.1.1: Prevalence of intestinal TB in adult indoor ASIO population of Peshawar Division, Pakistan $(n=207)$

\begin{tabular}{|c|l|c|c|c|c|}
\hline \multirow{2}{*}{ Variable } & \multirow{2}{*}{ Attributes } & \multicolumn{2}{|c|}{ Sample statistics } & \multicolumn{2}{c|}{$95 \% \mathrm{Cl}$ for proportion for population } \\
\cline { 3 - 6 } & & Count & Percentage & Lower & Upper \\
\hline \multirow{2}{*}{$\begin{array}{c}\text { Presence of } \\
\text { intestinal TB }\end{array}$} & Yes & 41 & $19.81 \%$ & 14.95 & 25.77 \\
\cline { 2 - 6 } & No & 166 & $80.19 \%$ & 74.23 & 85.05 \\
\hline \multicolumn{2}{|c|}{ Total } & 207 & 100.00 & \multicolumn{2}{|c}{ Population parameters } \\
\hline
\end{tabular}


3.1.2 Distribution of positive cases of ITB in adult indoor ASIO population across the sex and age group: The distribution of positive cases of ITB by sex and age group in adult indoor ASIO population of Peshawar Division is shown in Table 3.1.2. Here the frequency of ITB in sample and its estimated prevalence in population was higher in men $12.08 \%$ than women $7.73 \%$ and higher in age group $41-60$ years $11.60 \%$ than age group $18-60$ years $8.21 \%$.

\subsection{Hypotheses Testing:}

3.2.1 Observed vs. expected prevalence of ITB in adult indoor ASIO population $\left(\mathbf{H}_{01}\right)$ : Our observed counts for the presence of ITB (yes: no) were 41:166 from a sample of 207 against expected counts of $55: 160$ from a sample of 215 as reported by Maik, et al. ${ }^{2}$ from Jamshoro, Pakistan from June 2004 to June 2009. With different sample sizes/ denominators, comparison was not appropriate. Hence the expected counts and expected percentages were adjusted for a sample of 207. The expected counts of 55:215 were replaced by 52.95:154.05. Adjusted expected percentages came similar to expected percentages, so not changed. (Table 3.2.1.1)

Chi-square goodness of fit test showed p-value greater than alpha. $\mathrm{H}_{01}$ was declared as true and therefore accepted; showing that the observed prevalence is similar to the expected prevalence. Simply, the prevalence of $19.81 \%$ of ITB in our population is similar to what we were expecting from the adjusted expected percentage/ prevalence of $25.58 \%$ from Maik, et al. ${ }^{2}$ (Table 3.2.1.2)

3.2.2 Observed vs. expected distribution of positive cases of ITB by sex in adult indoor ASIO population $\left(\mathrm{H}_{02}\right)$ : Our observed distribution for men versus women was 25:16 out of 41 positive cases from a sample of 207 adult indoor ASIO patients against expected counts of 20:3 out of 23 positive cases of ITB in 513 adult indoor ASIO population

Table 3.1.2: Distribution of positive cases of intestinal TB across the sex and age groups in adult indoor ASIO population of Peshawar Division, Pakistan $(n=41 / 207)$

\begin{tabular}{|l|l|c|c|c|c|c|}
\hline \multirow{2}{*}{ Variables } & \multirow{2}{*}{ Attributes } & \multirow{2}{*}{$\begin{array}{c}\text { Sample } \\
\text { size }\end{array}$} & \multicolumn{3}{c|}{ Sample statistics } & \multicolumn{2}{c|}{$95 \% \mathrm{Cl}$ for proportion } \\
\cline { 4 - 7 } & & Count & Percentage & Lower & Upper \\
\hline \multirow{2}{*}{ Sex } & Men & 128 & 25 & $25^{*} 100 / 207=12.08 \%$ & 8.31 & 17.22 \\
\cline { 4 - 8 } & Women & 79 & 16 & $16 * 100 / 207=7.73 \%$ & 4.81 & 12.19 \\
\hline \multirow{2}{*}{ Age groups } & $18-40$ years & 187 & 17 & $17 * 100 / 207=8.21 \%$ & 5.19 & 12.75 \\
\cline { 2 - 7 } & $41-60$ years & 120 & 24 & $24 * 100 / 207=11.60 \%$ & 7.97 & 16.75 \\
\hline \multicolumn{2}{|c|}{ Total } & 207 & 41 & $41^{*} 100 / 207=19.81 \%$ & 7.56 & 8.64 \\
\hline
\end{tabular}

Table 3.2.1.1: Observed, expected and adjusted expected counts and percentages for prevalence of intestinal TB in adult indoor ASIO population of Peshawar Division, Pakistan $(n=207)$

\begin{tabular}{|l|l|c|c|c|c|c|}
\hline $\begin{array}{l}\text { Presence of } \\
\text { intestinal TB }\end{array}$ & $\begin{array}{l}\text { Observed } \\
\text { counts }\end{array}$ & $\begin{array}{c}\text { Observed } \\
\text { \%ages }\end{array}$ & $\begin{array}{c}\text { Expected } \\
\text { counts }\end{array}$ & $\begin{array}{c}\text { Expected } \\
\% \text { ages }\end{array}$ & $\begin{array}{c}\text { Adjusted expected } \\
\text { counts }\end{array}$ & $\begin{array}{c}\text { Adjusted expected } \\
\% \text { ages }\end{array}$ \\
\hline Yes & 41 & $19.81 \%$ & 55 & $25.58 \%$ & $55^{\star} 207 / 215=52.95$ & $52.95 * 100 / 207=25.58 \%$ \\
\hline No & 166 & $80.19 \%$ & 160 & $74.42 \%$ & $160 \star 207 / 215=154.05$ & $154.05 * 100 / 207=74.42 \%$ \\
\hline Total $(n)$ & 207 & $100 \%$ & 215 & $100.00 \%$ & 207.00 & $100.00 \%$ \\
\hline
\end{tabular}

Table 3.2.1.2: Observed vs. expected prevalence of intestinal TB in adult indoor ASIO population of Peshawar Division, Pakistan $(n=207)$

\begin{tabular}{|l|l|c|c|c|c|c|c|c|c|}
\hline Variable & Attributes & $\mathrm{O}$ & $\mathrm{E}$ & $\mathrm{O}-\mathrm{E}$ & $(\mathrm{O}-\mathrm{E})^{2}$ & $(\mathrm{O}-\mathrm{E})^{2} / \mathrm{E}$ & $\chi^{2}$ & d.f. & p-value \\
\hline \multirow{2}{*}{$\begin{array}{l}\text { Presence of } \\
\text { intestinal TB }\end{array}$} & Yes & 41 & 52.95 & -11.95 & 142.80 & 2.70 & 3.624 & 1 & .05695 \\
\cline { 2 - 9 } & No & 166 & 154.05 & 11.95 & 142.80 & 0.93 & $\mathrm{H}_{01}$ accepted at alpha .05 \\
\cline { 2 - 9 } & Total & 207 & 207.00 & \multicolumn{5}{|c|}{ Chi-square goodness of fit with Yates correction } \\
\hline
\end{tabular}

$\mathrm{O}=$ Observed count, $\mathrm{E}=$ Expected count, $\chi^{2}=$ chi-square statistic, d.f. $=$ degree of freedom 
as reported by Nguyen, et al. ${ }^{1}$ from Ho Chi Minh, Vietnam from 1992 to 1998. With different sample sizes/ denominators, comparison was not appropriate. Hence the expected counts and expected percentages were adjusted for a sample of 207. The expected counts of $20: 3$ were replaced by $35.65: 5.35$ and expected percentages of $3.90 \%: 0.58 \%$ were replaced by $17.22 \%: 2.59 \%$. (Table 3.2.2.1)

Chi-square goodness of fit test showed p-value $<$ alpha. $\mathrm{H}_{02}$ was declared as false and therefore rejected, showing that the observations did not match the expected values of the population. In simple words, our observed prevalence of ITB in men $12.08 \%$ was statistically lower to what we expected (adjusted expected) for men $17.22 \%$ \& our observed prevalence of ITB in women $7.73 \%$ was higher to what we expected (adjusted expected) for women $2.59 \%$ from Nguyen, et al. ${ }^{1}$ (Table 3.2.2.2)
3.2.3 Observed vs. expected distribution of positive cases of intestinal TB by age groups in adult indoor ASIO population $\left(\mathrm{H}_{03}\right)$ : Our observed distribution for age group 18-40 years versus 41-60 years was 17:24 out of 41 positive cases from a sample of 207 against expected counts of 7:16 in age group of 20-40 years versus $41-70$ years out of 23 positive cases of ITB in 513 adult indoor ASIO population as reported by Nguyen, et al. ${ }^{1}$ With different sample sizes/ denominators, comparison was not appropriate. Hence the expected counts and expected percentages were adjusted for a sample of 207. The expected counts of 7:16 were replaced by $12.48: 28.52$ and expected percentages of $1.36 \%: 3.12 \%$ were replaced by $6.03 \%: 13.78 \%$. (Table 3.2.3.1)

Chi-square goodness of fit test showed p-value >alpha. $\mathrm{H}_{02}$ was declared to be true and therefore accepted, showing that the observations match the

Table 3.2.2.1: Observed, expected and adjusted expected counts and percentages for distribution of positive cases of intestinal TB by sex in adult indoor ASIO population of Peshawar Division, Pakistan $(n=41 / 207)$

\begin{tabular}{|c|c|c|c|c|c|c|}
\hline $\begin{array}{c}\text { Presence of } \\
\text { intestinal TB }\end{array}$ & $\begin{array}{c}\text { Observed } \\
\text { counts }\end{array}$ & $\begin{array}{c}\text { Observed } \\
\text { \%ages }\end{array}$ & $\begin{array}{c}\text { Expected } \\
\text { counts }\end{array}$ & $\begin{array}{c}\text { Expected } \\
\% \text { ages }\end{array}$ & $\begin{array}{c}\text { Adjusted ex- } \\
\text { pected counts }\end{array}$ & $\begin{array}{c}\text { Adjusted expect- } \\
\text { ed \% }\end{array}$ \\
\hline $\begin{array}{c}\text { Positive cases } \\
\text { in men }\end{array}$ & 25 & $\begin{array}{c}25^{*} 100 / 207 \\
=12.08 \%\end{array}$ & 20 & $\begin{array}{c}20^{*} 100 / 513 \\
=3.90 \%\end{array}$ & $\begin{array}{c}20^{\star} 41 / 23 \\
=35.65\end{array}$ & $\begin{array}{c}35.65^{\star} 100 / 207 \\
=17.22 \%\end{array}$ \\
\hline $\begin{array}{c}\text { Positive cases } \\
\text { in Women }\end{array}$ & 16 & $\begin{array}{c}16^{*} 100 / 207 \\
=7.73 \%\end{array}$ & 3 & $\begin{array}{c}3^{*} 100 / 513 \\
=0.58 \%\end{array}$ & $\begin{array}{c}3^{*} 41 / 23 \\
=5.35\end{array}$ & $\begin{array}{c}5.35^{\star} 100 / 207 \\
=2.59 \%\end{array}$ \\
\hline Total positive & 41 & $\begin{array}{c}41^{*} 100 / 207 \\
=19.81 \%\end{array}$ & 23 & $\begin{array}{c}23^{*} 100 / 513 \\
=4.48 \%\end{array}$ & $\begin{array}{c}23.00 * 41 / 23 \\
=16.00\end{array}$ & $\begin{array}{c}41.00^{*} 100 / 207 \\
=19.81 \%\end{array}$ \\
\hline
\end{tabular}

Table 3.2.2.2: Observed vs. expected distribution of positive cases of intestinal TB by sex in adult indoor ASIO population of Peshawar Division, Pakistan $(n=41 / 207)$

\begin{tabular}{|c|c|c|c|c|c|c|c|c|c|}
\hline Variable & Attributes & $\mathrm{O}$ & $\mathrm{E}$ & $\mathrm{O}-\mathrm{E}$ & $(\mathrm{O}-\mathrm{E})^{2}$ & $(\mathrm{O}-\mathrm{E})^{2} / \mathrm{E}$ & $\mathrm{X}^{2}$ & $\mathrm{~d}$.f. & $\mathrm{p}$-value \\
\hline \multirow{3}{*}{ Sex } & Men & 25 & 35.65 & -10.65 & 1.74 & 113.42 & 24.382 & 1 & $<.00001$ \\
\cline { 2 - 9 } & Women & 16 & 5.35 & 10.65 & 1.74 & 113.42 & \multicolumn{2}{|c|}{$\mathrm{H}_{02}$ rejected at alpha .05} \\
\cline { 2 - 9 } & Total & 41 & 41.00 & \multicolumn{5}{c|}{ Chi-square goodness of fit test with Yates correction } \\
\hline
\end{tabular}

$\mathrm{O}=$ Observed count, $\mathrm{E}=$ Expected count, $\mathrm{X}^{2}=$ chi-square statistic, d.f. $=$ degree of freedom

Table 3.2.3.1: Observed, expected and adjusted expected counts and percentages for distribution of positive cases of intestinal TB by age groups in adult indoor ASIO population of Peshawar Division, Pakistan $(n=41 / 207)$

\begin{tabular}{|l|c|c|c|c|c|c|}
\hline $\begin{array}{l}\text { Presence of } \\
\text { intestinal TB }\end{array}$ & $\begin{array}{c}\text { Observed } \\
\text { counts }\end{array}$ & $\begin{array}{c}\text { Observed } \\
\text { \%ages }\end{array}$ & $\begin{array}{c}\text { Expected } \\
\text { counts }\end{array}$ & $\begin{array}{c}\text { Expected } \\
\% a g e s\end{array}$ & $\begin{array}{c}\text { Adjusted ex- } \\
\text { pected counts }\end{array}$ & $\begin{array}{c}\text { Adjusted } \\
\text { expected \% }\end{array}$ \\
\hline $\begin{array}{l}\text { Positive cases in age } \\
\text { group 18-40 years }\end{array}$ & 17 & $\begin{array}{c}17^{*} 100 / 207 \\
=8.21 \%\end{array}$ & 7 & $\begin{array}{c}7^{*} 100 / 513 \\
=1.36 \%\end{array}$ & $\begin{array}{c}7^{*} 41 / 23 \\
=12.48\end{array}$ & $\begin{array}{c}12.48^{*} 100 / 207 \\
=6.03 \%\end{array}$ \\
\hline $\begin{array}{l}\text { Positive cases in age } \\
\text { group 41-60 years }\end{array}$ & 24 & $\begin{array}{c}6^{*} 100 / 196 \\
=11.60 \%\end{array}$ & 16 & $\begin{array}{c}16^{*} 100 / 513 \\
=3.12 \%\end{array}$ & $\begin{array}{c}16^{*} 41 / 23 \\
=28.52\end{array}$ & $\begin{array}{c}28.52^{*} 100 / 207 \\
=13.78 \%\end{array}$ \\
\hline Total positive & 41 & $\begin{array}{c}16^{\star} 100 / 196 \\
=19.81 \%\end{array}$ & 23 & $\begin{array}{c}23^{*} 100 / 280 \\
=4.48 \%\end{array}$ & $\begin{array}{c}23^{*} 41 / 23 \\
=41.00\end{array}$ & $\begin{array}{c}16.00^{\star} 100 / 196 \\
=19.81 \%\end{array}$ \\
\hline
\end{tabular}


expected values of the population. It simply means that our observed prevalence of ITB in age group $18-40$ years $8.21 \%$ was statistically similar to what we were expecting for age group 20-40 years 6.03 $\%$ \& our observed prevalence of intestinal TB in age group $41-60$ years $11.60 \%$ was also similar to what we were expecting for age group $41-60$ years $13.78 \%$ (adjusted expected) by Nguyen, et al. ${ }^{1}$ (Table 3.2.3.2)

3.2.4 Association of presence of ITB to sex in adult indoor ASIO population $\left(\mathrm{H}_{04}\right)$ : Presence of ITB (dependent variable) to sex (independent variable) in adult indoor ASIO population was substantiated by chi-square test of association. Having p-value more than alpha, $\mathrm{H}_{04}$ was declared as true and therefore accepted, revealing that the presence of intestinal TB is independent of sex i.e. presence of ITB and sex are not associated to each other. (Table 3.2.4)

3.2.5 Association of presence of ITB to age groups in adult indoor ASIO population $\left(\mathbf{H}_{05}\right)$ : Presence of ITB (dependent variable) to age groups (independent variable) in adult indoor ASIO population was substantiated by chi-square test of association. Having p-value more than alpha, $\mathrm{H}_{05}$ was declared as true and therefore accepted, revealing that the presence of ITB is independent of age groups i.e. presence of ITB and age groups are not associated to each other. (Table 3.2.5)

Table 3.2.3.2: Observed vs. expected distribution of positive cases of intestinal TB by age groups in adult indoor ASIO population of Peshawar Division, Pakistan $(n=41 / 207)$

\begin{tabular}{|l|l|l|l|l|l|l|l|l|l|}
\hline Variable & Attributes & $\mathrm{O}$ & $\mathrm{E}$ & $\mathrm{O}-\mathrm{E}$ & $(\mathrm{O}-\mathrm{E})^{2}$ & $(\mathrm{O}-\mathrm{E})^{2} / \mathrm{E}$ & $\mathrm{X}^{2}$ & d.f. & $\mathrm{p}$-value \\
\hline \multirow{3}{*}{ Age groups } & $18-40$ years & 17 & 12.48 & 4.52 & 20.43 & 1.64 & 2.353 & 1 & .12501 \\
\cline { 2 - 9 } & $41-60$ years & 24 & 28.52 & -4.52 & 20.43 & 0.72 & $\mathrm{H}_{03}$ accepted at alpha .05 \\
\cline { 2 - 9 } & Total & 41 & 41.00 & \multicolumn{6}{|l}{ Chi-square goodness of fit test with Yates correction } \\
\hline
\end{tabular}

$\mathrm{O}=$ Observed count, $\mathrm{E}=$ Expected count, $\mathrm{X}^{2}=$ chi-square statistic, d.f. $=$ degree of freedom

Table 3.2.4: Association of presence of intestinal TB to sex in adult indoor ASIO population of Peshawar Division, Pakistan $(n=207)$

\begin{tabular}{|c|c|c|c|c|c|c|c|}
\hline \multirow{2}{*}{$\begin{array}{l}\text { Variable/ } \\
\text { Attributes }\end{array}$} & \multicolumn{3}{|c|}{ Presence of intestinal TB } & \multirow{2}{*}{$\begin{array}{l}\text { Rows } \\
\text { Total }\end{array}$} & \multirow{2}{*}{$x^{2}$} & \multirow{2}{*}{ d.f. } & \multirow{2}{*}{ p-value } \\
\hline & & Yes & No & & & & \\
\hline Sex & & $(E) \quad\left[X^{2}\right]$ & $\mathrm{O} \quad(\mathrm{E}) \quad\left[\mathrm{X}^{2}\right]$ & & \multicolumn{3}{|c|}{$\begin{array}{l}\text { Chi-square test of association with Yates } \\
\text { correction }\end{array}$} \\
\hline Men & 25( & $5.35)[0.00]$ & $103(102.65)$ [0.00] & 128 & \multirow{2}{*}{.016} & \multirow{2}{*}{1} & \multirow{2}{*}{.8992} \\
\hline Women & 16( & 5.65) [0.01] & 63 (63.35) [0.00] & 79 & & & \\
\hline Columns Total & & 41 & 166 & 207 & \multicolumn{3}{|c|}{$\mathrm{H}_{04}$ accepted at alpha 0.05} \\
\hline
\end{tabular}

$\mathrm{O}=$ Observed count, $\mathrm{E}=$ Expected counts, $\mathrm{X}^{2}=$ chi-square statistic, d.f. $=$ degree of freedom

Table 3.2.5: Association of presence of intestinal TB to age groups in adult indoor ASIO population of Peshawar Division, Pakistan $(n=207)$

\begin{tabular}{|c|c|c|c|c|c|c|}
\hline \multirow{2}{*}{$\begin{array}{l}\text { Variable/ } \\
\text { Attributes }\end{array}$} & \multicolumn{2}{|c|}{ Presence of intestinal TB } & \multirow{2}{*}{$\begin{array}{l}\text { Rows } \\
\text { Total }\end{array}$} & \multirow{2}{*}{$x^{2}$} & \multirow{2}{*}{ d.f. } & \multirow{2}{*}{ p-value } \\
\hline & Yes & No & & & & \\
\hline Age groups & $\mathrm{O} \quad(\mathrm{E}) \quad\left[\mathrm{X}^{2}\right]$ & $\mathrm{O} \quad(\mathrm{E}) \quad\left[\mathrm{X}^{2}\right]$ & & \multicolumn{3}{|c|}{$\begin{array}{l}\text { Chi-square test of association with } \\
\text { Yates correction }\end{array}$} \\
\hline $18-40$ years & $17(17.23)[0.00]$ & $70(69.77)[0.00]$ & 87 & \multirow{2}{*}{.0067} & \multirow{2}{*}{1} & \multirow{2}{*}{.9347} \\
\hline $41-60$ years & $24(23.77)[0.00]$ & $96(96.23)[0.00]$ & 120 & & & \\
\hline Columns Total & 41 & 166 & 207 & \multicolumn{3}{|c|}{$\mathrm{H}_{05}$ accepted at alpha 0.05} \\
\hline
\end{tabular}

$\mathrm{O}=$ Observed count, $\mathrm{E}=$ Expected count, $\mathrm{X}^{2}=$ chi-square statistic, d.f. $=$ degree of freedom 


\section{DISCUSSION}

4.1 Prevalence of ITB in adult indoor ASIO population $\left(\mathbf{H}_{01}\right)$ : The prevalence of ITB in our study was $19.81 \%(14.95 \%-25.77 \%$ at $95 \% \mathrm{CL})$. Almost similar prevalence $25.58 \%$ (within our $95 \% \mathrm{Cl}$ ) to our study was reported by Maik, et al. ${ }^{2}$ from Jamshoro, Pakistan from June 2004 to June 2009 in 215 ASIO patients.

Following five studies showed lower prevalence of intestinal TB than ours: Sultan, et al..$^{3}$ from Karachi, Pakistan from September 2016 to October 2019 reported $7.5 \%$ prevalence of intestinal TB in 120 intestinal obstruction cases. Tasnim, et al. ${ }^{4}$ from Rajshahi, Bangladesh from Sep 2010 to Aug 2011 showed $2.8 \%$ frequency of intestinal TB in 250 patients with intestinal obstruction

Chitumalla, et al. ${ }^{2}$ from Hyderabad, India from October 2013 to September 2015 elaborated 4.88\% ITB cases in 41 patients of ASIO. Adhikari, et al. ${ }^{2}$ from Calcutta, India from May 2005 to April 2008 demonstrated $14.17 \%$ intestinal Tb cases in 367 patients of acute intestinal obstruction. Nguyen, et al. ${ }^{1}$ from Ho Chi Minh, Vietnam from 1992 to 1998 $(n=513)$ highlighted $4.48 \%$ prevalence of ITB in intestinal obstruction. No study could be retrieved from the literature which shows higher prevalence of ITB than our study.

Our observed prevalence of ITB in adult indoor ASIO $19.81 \%$ from a sample of 207 was similar $(p=.5695)$ to what we expected as $25.58 \%$ from a study by Maik, et al. ${ }^{2}$ from Jamshoro, Pakistan from a sample of 215.

4.2 Distribution of positive cases of ITB in adult indoor ASIO population by $\operatorname{sex}\left(\mathbf{H}_{02}\right)$ : The prevalence of ITB in our study was more in men $12.08 \%$ $(95 \% \mathrm{Cl} 8.31-17.22)$ than women $7.73 \%(95 \% \mathrm{Cl}$ 4.81-12.19). Similarly higher prevalence in men as $3.90 \%$ and lower prevalence in women as $0.58 \%$ was shown by Nguyen, et al. ${ }^{1}$ from Ho Chi Minh, Vietnam from 1992 to $1998(n=513)$.

Our observed prevalence of ITB in men $12.08 \%$ was lower to what we expected (adjusted expected) for men $17.22 \%$ \& our observed prevalence of ITB in women $7.73 \%$ was higher to what we expected (adjusted expected) for women $2.59 \%$ from Nguyen, et al. ${ }^{1}$ from Ho Chi Minh, Vietnam from 1992 to 1998 $(\mathrm{n}=513)$ (Table 3.2.2.2)

4.3 Distribution of positive cases of ITB in adult indoor ASIO population by age groups $\left(\mathrm{H}_{03}\right)$ : The prevalence of ITB in our study was more in age group $41-60$ years $11.60 \%(95 \% \mathrm{Cl} 7.97-16.75)$ than age group $18-40$ years $8.21 \%$ (95\% Cl 5.19-12.75). Similarly higher prevalence in age group 41-70 years as $3.12 \%$ and lower prevalence in age group 18-40 years as $1.36 \%$ was shown by Nguyen, et al. ${ }^{1}$ from
Ho Chi Minh, Vietnam from 1992 to $1998(n=513)$.

Our observed prevalence of ITB in age group 18-40 years $8.21 \%$ was statistically similar to what we were expecting for age group 20-40 years $6.03 \%$ \& our observed prevalence of ITB in age group 41-60 years $11.60 \%$ was also similar to what we were expecting for age group 41-60 years 13.78\% (adjusted expected) by Nguyen, et al. ${ }^{1}$ from Ho Chi Minh, Vietnam from 1992 to 1998. (Table 3.2.3.2)

4.4 Association of presence of ITB to sex in adult indoor ASIO population $\left(\mathrm{H}_{04}\right)$ : In our study there was no association between the presence of ITB and sex (Table 3.2.4, $p=$.8992). No study could be drawn from literature to compare with our study.

4.5 Association of presence of ITB to age groups in adult indoor ASIO population $\left(\mathrm{H}_{05}\right)$ : In our study presence of ITB and age groups were not associated to each other (Table 3.2.5, $p=.9347$ ). No study could be drawn from literature to compare with our study.

\section{CONCLUSIONS \& RECOMMENDATION}

Prevalence of intestinal TB in adult indoor acute mechanical small intestinal obstruction (ASIO) population of Peshawar Division, Pakistan was 19.81\%. It was more in men than women and more in 41-60 years than $18-40$ years age group population. Overall prevalence of intestinal TB was similar to expected. Observed distribution across sex was different and across age groups was similar to expected. Presence of intestinal TB was not associated to sex and age groups respectively.

Health care providers specifically surgeons should have low threshold for intestinal TB in adult indoor ASIO population in high TB prevalent areas like Pakistan, send intestinal specimens/biopsies for histopathology, culture and PCR to early diagnose intestinal TB and start its management as early as possible to prevent morbidity and mortality.

Acknowledgement: We are thankful to Dr. Muhammad Marwat from Gomal Medical College, D.I.Khan for granting us permission to use his "Marwat Logical Trajectory of Research Process".

\section{REFRENCES}

1. Mucha P Jr. Small intestinal obstruction. Surg Clin North Am 1987 Jun; 67(3):597-620. https:// doi.org/10.1016/S0039-6109(16)44234-9

2. Miller G, Boman J, Shrier I, Gordon PH. Natural history of patients with adhesive small intestinal obstruction. Br J Surg 2000 Sep; 87(9):1240-7. https://doi.org/10.1046/j.13652168.2000.01530.x

3. Miller G, Boman J, Shrier I, Gordon PH. Etiology of small intestinal obstruction. Am J Surg 2000 Jul; 180(1):33-6. https://doi.org/10.1016/S00029610(00)00407-4 
4. Cappell MS, Batke M. Mechanical obstruction of the small intestinal and colon. Med Clin North Am 2008 May; 92(3):575-97. https://doi. org/10.1016/j.mcna.2008.01.003

5. Gore RM, Silvers RI, Thakrar KH, Wenzke DR, Mehta UK, Newmark GM, et al. Intestinal Obstruction. Radiol Clin North Am 2015 Nov; 53(6):1225-40. https://doi.org/10.1016/j. rcl.2015.06.008

6. Ray NF, Denton WG, Thamer M, Henderson SC, Perry S. Abdominal adhesiolysis: inpatient care and expenditures in the United States in 1994. J Am Coll Surg 1998 Jan; 186(1):1-9. https://doi. org/10.1016/S1072-7515(97)00127-0

7. Markogiannakis $\mathrm{H}$, Messaris $\mathrm{E}$, Dardamanis D, Pararas N, Tzertzemelis D, Giannopoulos P. Acute mechanical intestinal obstruction: clinical presentation, etiology, management and outcome. World J Gastroenterol 2007 Jan 21; 13(3):432-7. https://doi.org/10.3748/wjg.v13. i3.432

8. Adhikari S, Hossein MZ, Das A, Mitra N, Ray $U$. Etiology and outcome of acute intestinal obstruction: a review of 367 patients in Eastern India. Saudi J Gastroenterol 2010 Oct-Dec; 16(4):285-7. https://doi.org/10.4103/13193767.70617

9. World Health Organization. Global tuberculosis report 2019 [accessed 2020 Apr 8]. Available at: https://www.who.int/tb/publications/global_report/en/

10. National TB Control Program. National guidelines for control of tuberculosis in Pakistan [revised and updated 2019, cited 2020 Apr 24]. Available at: http://ntp.gov.pk/ntp-old/uploads/ National_Guidelines_for_TB_Revised_2019

11. McQueen KR. Gastrointestinal disorders. In: Papadakis MA, McPhee SJ, Rabow MW, editors. Current medical diagnosis \& treatment. 57th ed. New York: McGraw-Hill; 2018.p.586-684.

12. Kim MP, Janz BA, Kasparian AS. Tuberculosis enteritis presenting as a small intestinal obstruction. J Am Coll Surg 2005 Sep; 201(3):478-9. https://doi.org/10.1016/j.jamcollsurg.2005.02.032

13. Ha HK, Ko GY, Yu ES, Yoon K, Hong WS, Kim HR. Intestinal tuberculosis with abdominal complications: radiologic and pathologic features. Abdom Imaging 1999 Jan-Feb; 24(1):32-8. https://doi.org/10.1007/s002619900436

14. Choudhary L, Bhat NS, Shahi KS. Clinico-Pathological profile and surgical management of tubercular small intestinal obstruction. Int Surg J 2018; 5(11):3553-7. https://doi. org/10.18203/2349-2902.isj20184621

15. Nguyen $\mathrm{VH}$. Intestinal obstruction due to tuberculosis. Asian J Surg 2002 Apr; 25(2):145-8. https://doi.org/10.1016/S1015-9584(09)60163-9

16. Chitumalla PK, Vemulapally NK, Reddy SN. Clin- ical study of intestinal obstruction in relation to etiological factors. Int Surg J 2017; 4(2):485-90. https://doi.org/10.18203/2349-2902.isj20164846

17. Tasnim T, Rahman MM, Alam A, Laila R, Matin A, Nafisa A. Current spectrum of intestinal obstruction in a teaching hospital. TAJ: J Teachers Assoc [Internet] 2019 Jun [cited 2020 May 21] ; 32(1):62-9. https://doi.org/10.3329/taj. v32i1.42737

18. Malik MA, Shah M, Sufi K. Pattern of acute intestinal obstruction: is there a change in the underlying etiology. Saudi J Gastroenterol 2010; 16(4):272-4. https://doi.org/10.4103/13193767.70613

19. Sultan A, Hassan M, Ali M. Role of multidetector computed tomography with multiplanar and curved multiplanar reformations in the detection of cause of intestinal obstruction: A tertiary care experience. Cureus 2020 Mar 29; 12(3):e7464. https://doi.org/10.7759/cureus.7464

20. Ghori MR, Khan $\mathrm{H}$, Marwat M. Distribution of non-malignant hematological disorders by sex, age groups and type of disease based on bone marrow aspiration in population of Khyber Pakhtunkhwa, Pakistan. Gomal J Med Sci 2019 Apr-Jun; 17 (2): 29-36. https://doi.org/10.46903/ gjms/17.02.1926

21. Ain N, Khan S, Marwat M, Khan N, Ahmad I, Ramzan $\mathrm{F}$, et al. Frequency, distribution and determinants of hypertension in adult stroke population of D.I.Khan Division, Pakistan. Gomal J Med Sci 2019 Jul-Sep; 17 (3):81-9. https://doi. org/10.46903/gjms/17.03.2076

22. Khalid MK, Ahmad I, Khan MA, Sharjeel M, Irfan M. Marwat M. Distribution of pediatric cataracts by sex, age groups, laterality, type and presentation in population of D.I.Khan District, Pakistan. Gomal J Med Sci 2019 Oct-Dec; 17 (4):123-30. https://doi.org/10.46903/gjms/17.04.2025

23. Marwat M, Ahmad I, Ashiq F, Ali S, Zamir S, Rehman MU, et al. Frequency, distribution and determinants of diabetes mellitus in adult acute coronary syndrome population of D.I.Khan Division, Pakistan. Gomal J Med Sci 2019 OctDec; 17 (4):131-43. https://doi.org/10.46903/ gjms/17.04.2106

24. Raosoft $\circledast$ sample size calculator [internet]. Seattle, WA, USA: Raosoft Inc.; 2004. [accessed 2020 Apr 13]. Available at: http://www. raosoft. com/samplesize.html

25. Statistics Kingdom. Proportion confidence interval calculator [internet]. Statistics Kingdom; Melbourne, Australia 2007. [accessed 2020 May 7]. Available at: http://www.statskingdom. com/41_proportion_confidence_interval.html

26. Zar JH. Biostatistical Analysis. 5thed. New York: Prentice-Hall, Inc.

27. Daniel WW. Biostatistics: A Foundation for Analysis in the Health Sciences. 7th ed. Singapore: John Wily; 2005. 
28. Social Science Statistics. Statistical Tests Calculators [Internet]. [accessed 2020 May 12]. Available at: https://www.socscistatistics.com/ tests/goodnessoffit/default2.aspx
29. Social Science Statistics. Statistical Tests Calculators [Internet]. [accessed 2020 Apr 12]. Available at: https://www.socscistatistics.com/ tests/chisquare2/default2.aspx
CONFLICT OF INTEREST

Authors declare no conflict of interest. GRANT SUPPORT AND FINANCIAL DISCLOSURE None declared.

\section{AUTHORS' CONTRIBUTION}

The following authors have made substantial contributions to the manuscript as under:

Conception or Design:

Acquisition, Analysis or Interpretation of Data:

Manuscript Writing \& Approval:

\section{$\mathrm{AH}, \mathrm{SMIA}$}

AH, SMIA, IU, SA, MFK, MS

AH, SMIA, IU, SA, MFK, MS

All the authors agree to be accountable for all aspects of the work in ensuring that questions related to the accuracy or integrity of any part of the work are appropriately investigated and resolved. 